\title{
SURGICAL TREATMENT OF PENOSCROTAL ELEPHANTIASIS: A CASE REPORT
}

Dhawan Rishi¹, Garg Ramneesh², Aulakh Baldev³, Uppal Sanjeev4, Mittal Rajinder ${ }^{5}$, Gupta Avinash ${ }^{6}$

\section{HOW TO CITE THIS ARTICLE:}

Dhawan Rishi, Garg Ramneesh, Aulakh Baldev, Uppal Sanjeev, Mittal Rajinder, Gupta Avinash. "Surgical Treatment of Penoscrotal Elephantiasis: A Case Report". Journal of Evolution of Medical and Dental Sciences 2014; Vol. 3, Issue 36, August 18; Page: 9549-9552, DOI: 10.14260/jemds/2014/3234

ABSTRACT: Elephantiasis is a disease of the tropical areas of the world caused by obstruction of the lymphatic channels by the filarial worms. The most common worm causing elephantiasis is the Wuchereria Bancrofti. The disease is not uncommon in tropical countries especially India. Involvement of peno scrotal region with elephantiasis is a rarity. We describe here a surgically treated case of penoscrotal elephantiasis.

KEYWORDS: Elephantiasis, penoscrotal, grafting.

CASE REPORT 1: Elephantiasis or filariasis is a disease of the tropical areas of the world, caused by recurrent lymphangitis and subsequent obstruction of the lymphatic channels by filarial worms, leading to edema of the areas drained by these channels.(1-3) The disease is caused by bites of mosquito containing infective larval stage of filarial worms. These larvae then migrate through dermal lymphatics and grow into adult worms.

The lymphangitis caused by these worms leads to fibrosis and lymphatic blockade. The most common worms causing elephantiasis are the Wuchereria Bancrofti causing $90 \%$ of the disease. Other causes are the Brugia Malai and B Timori. In India also W Bancrofti is the most common cause and is endemic in almost whole of Indian peninsula, especially in state of Orissa, Andhra Pradesh and Bihar.

The treatment of Filariasis includes a single dose of Albendazole $400 \mathrm{mg}$ along with Diethylcarbamazine citrate (D. E. C.) $6 \mathrm{mg} / \mathrm{Kg}$, which kills both adult and microfilarial forms of the worm. However this does not relieve the lymphatic edema associated with the disease, which has to be dealt by surgical means.

The penoscrotal region is drained by the lymphatics to the superficial inguinal lymph nodes. The blockade of these lymphatics leads to penoscrotal elephantiasis. The treatment of penoscrotal elephantiasis is excision of the diseased skin and coverage of the denuded area of the penile shaft with a split thickness skin graft and scrotoplasty.

We describe here a surgically treated case of penoscrotal elephantiasis.

CASE REPORT 2: A 37 yr. old male, a migrant laborer from Bihar, was admitted with progressively increasing penoscrotal swelling over the past ten years. The patient had no other co-morbidities and complained of only difficulty in walking and inability to perform sexual functions due to the increasing size of the penis and the scrotum. The patient had history of being given anti filarial treatment at his native place.

On physical examination the patient had a poor hygiene, had elephantiasis of the penis and the scrotum with gross hypertrophy of the penoscrotal skin and increased skin rugae (Fig 1). A skin biopsy taken preoperatively showed thickening and edema of the dermis and the epidermis. 
With a diagnosis of penoscrotal elephantiasis the patient was taken for surgery. The penile skin was excised first by giving a dorsal incision over the skin of the prepuce (Fig 2). The skin was supported by a finger in the thickened prepuceal skin. The incision was extended till the base of the penis and then curved around the base on both sides to remove the thickened skin of the scrotum at its junction with the normal looking skin. The spermatic cords on both sides were preserved by palpating and sparing them. After completely removing the diseased skin the penis and the scrotum were bare and there was no edema or thickening of the underlying structures (Fig 3).

The two testes were sutured together with absorbable sutures in the midline. The skin flaps were raised on both sides till the inguinal crease and the mobilized skin used to cover the testes so that the suture line comes to lie in the midline to simulate the median raphae. A corrugated drain was placed under the flaps to prevent a hematoma or seroma formation. The penile shaft was covered with a split thickness skin graft circumferentially and the two ends of the graft stapled in the midline inferiorly to lie in the line with the neo-scrotal suture line (Fig 4). The results of the procedure were extremely satisfactory for the patient as well as the surgeon.

DISCUSSION: Lymphatic filariasis infects around 120 million people in 72 countries and one third of the total burden of the disease lies in India. [1] Various procedures have been described for the treatment of filariasis but all have only limited benefit. [2] Various surgical procedures have been described for treatment of lympodema following filariasis. Lymphangioplasty was described by Handley in 1908 by passing long linen or silk threads from edematous tissues to healthy tissues with an expectation of developing new lymphatic channels along these threads. [3]

There was not much benefit found from this procedure. Kondoleon procedure was described in 1912. It consisted of en bloc excision of subcutaneous tissue and fascia lata from the trochanter till the external malleolus. ${ }^{[4]}$ This was modified by Sistrunk to include the same amount of skin along with subcutaneous tissue thus leaving no hanging skin..[5] Debulking procedures have been decribed by Charles, Homans, survelle and Thompson.[6,7]

Lymph nodovenous shunt (LNVS) is also shown to have some results. Dhanpat et al in a comparative study concluded that LNVS was effective in $62 \%$ cases of lymphedema of leg but Charles operation for debulking was required in late cases. Similarly the treatment of penoscrotal elephantiasis was described in a series of 48 patients over a decade with excision of the diseased skin and split thickness grafting by Singh V et al in 2011 with excellent results. [8]

Prica described radical excision of the affected tissue in penoscrotal elephantiasis followed by functioning lymphatic drainage into deep muscle compartment of thigh using a proximally based myocutaneous Gracilis flap. No recurrence and satisfying aesthetic and functional results were described in a series of 9 patients. [9]

We in our patient applied skin grafting for the shaft of penis and raised adjacent skin flaps to cover the scrotum. We left the inner perpuceal skin intact and sutured it with the distal end of the split skin graft, which retained its normal sensation. There was no recurrence of lymphedema or any complication after 6 months follow up of the patient.

CONCLUSION: Excision of the affected skin in penoscrotal elephantiasis with split skin graft of the shaft of penis leaving the inner normal perpuceal skin is a simple and safe procedure. 


\section{CASE REPORT}

The results are gratifying in both aesthetic and functional aspects, both for the patient and the surgeon. Similarly skin flaps can be easily raised from the skin of the surrounding groin to effectively cover the testis.

\section{REFERENCES:}

1. www.who.int/mediacentre/factsheets/fs102/en/ January 2012.

2. Manokaran G. Management of general manifestations of lymphatic filariasis. I J Urol 2005; 21: 39-43.

3. Handley S. Lymphangioplasty. Lancet 1908; 1:783-785.

4. Green TM. Elephantiasis and the Kondoleon Operation. Annals of Surgery 1920; 71: 28-31.

5. Sistrunk WE. Further Experiences with the Kondoleon Operation of Elephantiasis. Journal of the American Medical Association 1918; 72: 800.

6. Homans J. Treatment of Elephantiasis of the Legs.New England Journal of Medicine 1936; 215: 1099-1104.

7. Charles RH. A System of Treatment. In: Latham A. and English TC (ed), Vol. III, J\&A, Churchill, London 1912; p. 504.

8. Singh V, Sinha RJ, Sankhwar SN, Kumar V. Reconstructive surgery for penoscrotal filarial lymphedema: a decade of experience and follow-up. Urology. 2011; 77 (5):1228-31.

9. Prica S, Donati OF, Schaefer DJ, Peltzer J. Genital elephantiasis: reconstructive treatment of penoscrotal lymphedema with a myocutaneous M. gracilis flap. Experiences from a District Hospital in Ethiopia. Handchir Mikrochir Plast Chir. 2008; 40 (4): 272-8.

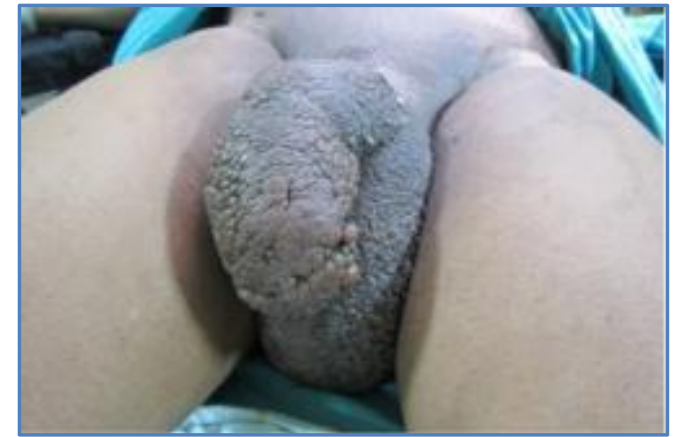

Fig. 1

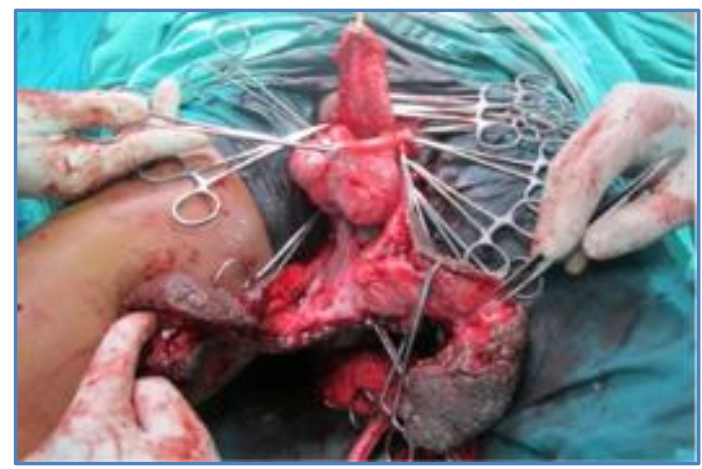

Fig. 3

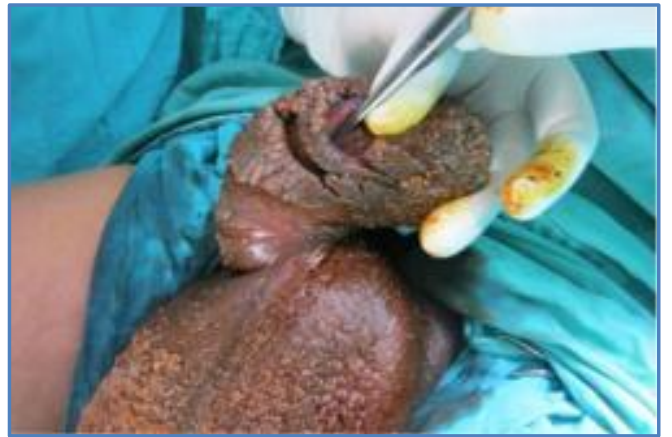

Fig. 2

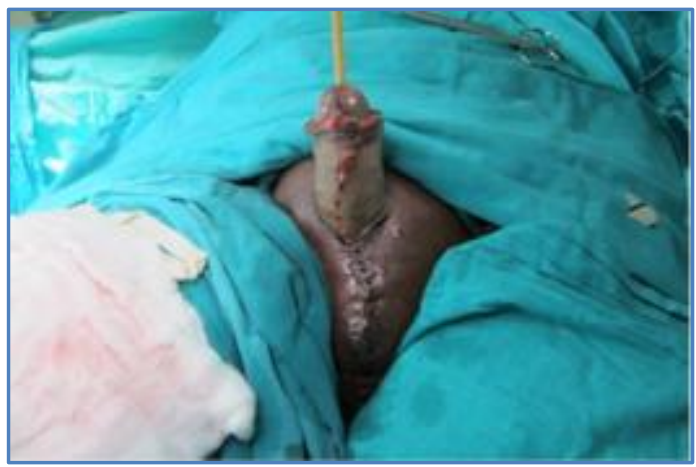

Fig. 4 


\section{CASE REPORT}

\section{AUTHORS:}

1. Dhawan Rishi

2. Garg Ramneesh

3. Aulakh Baldev

4. Uppal Sanjeev

5. Mittal Rajinder

6. Gupta Avinash

\section{PARTICULARS OF CONTRIBUTORS:}

1. Resident, Department of Plastic Surgery, Dayanand Medical College \& Hospital, Ludhiana, Punjab, India.

2. Assistant Professor, Department of Plastic Surgery, Dayanand Medical College \& Hospital, Ludhiana, Punjab, India.

3. Professor, Department of Urology, Dayanand Medical College \& Hospital, Ludhiana, Punjab, India.

4. Professor and HOD, Department of Plastic Surgery, Dayanand Medical College \& Hospital, Ludhiana, Punjab, India.
5. Professor, Department of Plastic Surgery, Dayanand Medical College \& Hospital, Ludhiana, Punjab, India.

6. Resident, Department of Plastic Surgery, Dayanand Medical College \& Hospital, Ludhiana, Punjab, India.

\section{NAME ADDRESS EMAIL ID OF THE CORRESPONDING AUTHOR:}

Dr. Ramneesh Garg,

House No. 183-A,

Sarabha Nagar,

Ludhiana-141001,

Punjab, India.

Email: ramneeshgarg@yahoo.com

Date of Submission: 02/08/2014.

Date of Peer Review: 04/08/2014.

Date of Acceptance: 12/08/2014.

Date of Publishing: 18/08/2014. 